\title{
The Influence of Organizational Structure on Teacher Empowerment: A Case Study of a Title I Elementary School
}

\author{
Dr. Marci B. Vining \\ Valdosta State University \\ 1500 N. Patterson St., Valdosta, GA, 31698 \\ United States \\ Dr. William F. Truby \\ Associate Professor \\ Valdosta State University \\ 1500 N. Patterson St., Valdosta, GA, 31698 \\ United States \\ Dr. Rudo E. Tsemunhu \\ Associate Professor \\ Valdosta State University \\ 1500 N. Patterson St., Valdosta, GA, 31698 \\ United States \\ Dr. Robert B. Green \\ Professor \\ Valdosta State University \\ 1500 N. Patterson St., Valdosta, GA, 31698 \\ United States \\ Dr. John D. Lairsey \\ Adjunct Professor \\ Valdosta State University, \\ 1500 N. Patterson St., Valdosta, GA, 31698 \\ United States \\ Dr. Kelly C. Dreger \\ Valdosta State University, \\ 2823 Meredyth Dr., Box 70751, Albany, GA, 31707 \\ United States
}

\begin{abstract}
This instrumental case study design addressed the lack of improvement in Georgia's Title I elementary schools. The purpose was to determine if organizational structure influenced empowerment and collaboration among teachers. Using Covey's Maturity Continuum as the metric, teachers in a low-performing elementary school were interviewed regarding the impact of organizational structure on their abilities to work effectively together. The researcher found that the hierarchal structure created by administrators influenced Title I teachers to work dependently. The structure created by the administrators did not promote interdependency. The imposed structure included mandatory protocols, definitive decision-making, absolute expectations, and lines of authority. It was concluded, however, that this structure did not significantly influence bottom-line measures of success. The findings in this study can provide national policy makers, departments of education, teacher preparation programs, and education units with research and insights on how to better structure American schools.
\end{abstract}

Keywords: organizational structure, teacher empowerment, elementary performance, organizational theory 


\section{Introduction}

After years of investing considerable amounts of effort, time, and other valuable resources, lack of improvement continues to persist in Georgia's Title I elementary schools based on levels of academic achievement as indicated by accountability measures (Nelson \& Guerra, 2014; Rogers-Chapman, 2015; Waddell, 2011; Wilson \& Strassfeld,2015).Jimenez-Castellanos (2010) argued in the last 30 years "educational outcomes still have not improved" (p. 352). Yet evidence suggested mandated responses such as strategic use of funding and higher accountability systems were minimally effective in improving academic achievement of Title I students (Rogers-Chapman, 2015; Waddell,2011). The Governor of Georgia, Nathan Deal, emphasized that70\% of failing schools served elementary-aged students. He found the status quo to be unacceptable (Office of the Governor, 2017). He remarked, "If this pattern of escalation in the number of failing schools does not change, its devastating effects on our state will grow with each passing school year" (Office of the Governor,2017, para. 41). The root cause is not the lack of resources but possiblya structural problem impeding on teachers' abilities to meet their full potentials (Bolman \& Deal,2013).

\subsection{Purpose}

Teachers, and the organizational structure in which they work, matter in the commitment to improve academic achievement (Bolman \& Deal, 2013).The purpose of this study was to determine the degree to which teachers were empowered by a school's organizational structure to effectively work together in a Title I elementary school.According to Covey (2004), the ability to effectively work together progresses through three levels of maturity. Covey (2004) defined these levels as dependence, independence, and interdependence. He believed interdependent behaviors empower individuals to achieve optimum results towards collective goals.A key component to supporting interdependence among team members and leaders is a helpful school structure (Bolman \& Deal, 2013; Covey, 2004).

\subsection{Significance of the Study}

This study addressed the lack of improvement in Georgia's Title I elementary schools. The findings in this study can inform policy makers, departments of education, teacher preparation programs, and education organizations on how to better structure schools allowing teachers in low-performing Title I schools to more effectively work together. The findings of this study may support educational leaders in confronting the challenge of improving academic achievement in low-performing schools.

\subsection{Conceptual Framework}

The premise for conducting this research began with an interest in Stephen Covey's Maturity Continuum (Covey, 2004). The Maturity Continuum is a hierarchy of three levels of maturity identified as dependent, independent, and interdependent (Covey, 1996, 2004; Green, 2000). At the lowest level of maturity, dependence is observable when individuals borrow power from authority or position. Independence is recognizable when individuals acquire personal power. Dependence and independence are prerequisites to achieving interdependence, the highest level of the hierarchy.Interdependence is perceived as power dispersed to the individual and team, which is also the governing principle of empowerment.

Covey's Maturity Continuum was used to understand how teachers perceived the organizational structure of a lowperforming Title I school. Organizational leaders develop empowerment by creating conditions conducive to productive, interdependent relationships (Covey, 2004). Empowered employees expend maximum potential to achieve the mission and goals of their organizations (Covey,2004).Covey's Maturity Continuum was used to measure the degree of empowerment to determine the influence of the school's organizational structure on teachers' ability to work effectively together.

In addition to perceptions of maturity level, this study also used Bolman and Deal's (2013) structural perspective to frame the conditions of the selected organization. Bolman and Deal (2013) described two basic structural decisions necessary to design an effective organization. These included appropriate division of labor and suitable forms of coordination and control. Making sense of issues related to the organization's structure required describing the conditions, procedures, and responsibilities within the organizational design. According to Bolman and Deal's (2013) structural frame, examining an organization requires looking "beyond individuals to examine the social architecture of work" (p. 66).Examining the strengths and limitations of the structural design rather than individual skills and attitudes was meant to identify flaws impeding effective organizational performance (Bolman \& Deal, 2013).

\section{Methodology}

The central concept of this study was empowerment, operationally defined as responsibility (job roles) and authority (access to information, resources, and decision-making).Case study design fit the purpose and research questions of this study. 
The focus was to explore a case in depth enough to gain an understanding of the influence of organizational structure in a particular low-performing Title I school. According to Merriam (2002), the case study research process begins with determining a special case for investigation. Trying to understand the theoretical framework of Bolman and Deal (2013) and Covey (1996) through a particular case required use of the instrumental case study design. The school selected for this study was unique in that it was the lowest-performing elementary school within a particular Regional Education Service Agency (RESA) district.

Six teachers were selectedfor interviews to explore the research questions. Data collected from a self-inventory survey was first used to identify teachers at various levels of empowerment for individual interviews. The survey protocol included questions adapted from Covey (1996). The selection process involved multiple-case sampling techniques from Miles, Huberman, and Saldana (2014). Multiple-case sampling was used to select teachers who could provide the most balanced, in-depth coverage of the research questions. Participants were visited three times during November and December 2017 for interviews. A list of open-ended questions guided the interview process using Bolman and Deal's (2013) structural theory. During the interviews, participants shared their perceptions and experiences at an identified low-performing Georgia Title I elementary school. Narrative profiles were created to gain a sense of participant identities. The profiles were based on recommendations from Seidman (2006). The development process for them involved rereading the transcripts, notating passages, and writing a coherent story of the interview process for each participant.

Analysisof interview data involved coding meaningful words to find consistency among the data and determine themes.Three coding cycles were conducted for viewing and analyzing transcripts (Miles, Huberman, \& Saldana, 2014). The initial coding cycle familiarized the researcher with the lived experience of each participant. Interview data weremarked and labeled using a sequential approach to write narrative profiles. Following prioritizing historical accounts of participants for the narrative profiles, the researcher assigned descriptive, in-vivo, and provisional codes to words, short phrases, and extended sections of interview data and researcher memos. The third coding cycle delved deeper into the data by analyzing summary codes and grouping them into smaller categories. A matrix was created to visualize the data, which was categorized into sets based on themes from the data. From this data, a structural configuration of the site was created. The structural model included major themes to demonstrate how the relationships among teachers and organizational structure relate to empowerment.

Table 1 shows a sample of the matrix used to code data for the concept of centralized structure and its subcategories. This matrix enabled the researcher to organize thematic discussion pertaining to theoretical and substantive categories. Interview and observation data provided information to address the research problem by synthesizing individual perspectives and discovering what actually occurred in a low-performing Title I school in Georgia.

\section{Discussion of Themes}

Using qualitative methods, the researcher investigated teachers' perceptions and experiences in one low-performing Title I school in Georgia. Five analytical themes used to characterize the degree to which teachers understood their empowerment were: (1) Simple Hierarchy: Chain of Command, (2) The Decision-Making Process, (3) The Nature of Teamwork, (4) The Maturity Continuum, and (5) The Human Resource Frame. These themes emerged from a thorough examination of all data collected in this study.

Figure 1below represents the school structure based on perceptions from the participants. Participants shared a sense of participation in school-based decisions through a supportive structural design. They described a collective belief in a formal structure as a means of collaboration and communication. This structure includes regularly scheduled times for teachers to meet and a communication channel for exchanging ideas. Teachers do not feel powerless because the structure is not rigidor controlled by administrators. Participants described limited access to the top levels of the hierarchy, which may explain individual missions based on organizational goals. The design may suggest that departmentalization of content created by formalized roles encourages independence, as communication channels are vague between grade level and content teams. The school's model represents a modification of Bolman and Deal's (2013) simple hierarchy. This model adds a level to the hierarchy consisting of committees that are based on school goals. The lines show communication of information among the group.

A chain of command consisted of administrators controlling the decision-making process through a channel of communication. This communication network was comprised of lines of authority beginning with administrators who pushed down decisions to teachers. Input regarding decisions flows back up the channel, but administrators were the ultimate decision-makers for the school. The inability to make meaningful decisions was a behavior related to lower levels of empowerment. Teachers displayed independent levels based on Covey's Maturity Continuum. 
The chain of command with limited access to power sharing may have contributed to teachers' independent thinking, as they worked in silos to achieve personal victories.

\section{Findings and Conclusions}

In this section, a discussion of the findings will take place to facilitate understanding of participants' experiences. This section is sorted by the research questions guiding the study. The research questions are answered based on the perceptions of the participants.

\subsection{RQ1: What are the life and career experiences of teachers at an identified low-performing Georgia Title I elementary school?}

Perceptions of the life and career experiences of teachers at an identified low-performing Georgia Title I elementary school convey the context and clarify intentions of the participants. The researcher came to know the participants through their personal experiences leading up to current working conditions at the research site. Categories were developed based on individual profiles modeled after Seidman (2006)as well as the view of the research pertaining to experiences in the teaching profession. The life and career experiences were the following:

- Years of Experience. Teaching experience is positively related to academic achievement as measured by standardized tests (Kini \& Podolsky, 2016).The total amount of teaching experience among the participants was 87 years. The lowest number for teaching experience was 12 years (two participants) and the highest number for teaching experience was 17 years (one participant). The majority of participants' experiences were at the research site. One participant shared that administrators changed more than members of the staff. This encouraged teachers to bond together.

- Teaching Certification. All of the participants were certified teachers. Certification status is a variable of teacher quality impacting academic achievement. At the simplest level, schools receive funding based on indicators of highly qualified teachers including number of teachers holding a clear, renewable Georgia certificate who currently teach in their field of certification (Hourigan, 2011). The presence of a highly qualified teacher does not increase the likelihood of teacher effectiveness (Smith \& Gorard, 2007).However, the collective years among participants deserved consideration as researchers included appraisal of teacher quality as a vital component of organizational success (Goe \& Stickler, 2008; Looney, 2011).

- Collaboration. Working in isolation is an obsolete phenomenon in describing effective teacher performance (Daft, 2013; Greenwood \& Miller, 2010).Participants described working in isolation relative to job descriptions. They described independent skills impacting organizational effectiveness, including response to data-driven and lesson planning protocols. Participants defined collaboration in the context of meeting weekly with team members to improve performance targets. Teachers collaborating at scheduled times with protocols indicated a formal structural consideration (Bolman \& Deal, 2013). These protocols included a data questionnaire and lesson planning template.

- Family. Participants described functioning as a family taking pride in their traditions. They valued the person more than just another professional. Participants had the responsibility to "check on one another." Teachers leaned on each other to cope with changes in administrative "thinking." Another tradition involved valuing students as "a whole kid" rather than viewing them asjust a standardized test score. Meeting the emotional needs of students was "the heart of teaching." Participants shared the importance of improved academic achievement, but they emphasized student comfort and happiness as the fundamental measure of success.

- Self-Managed Teams. Researchers described self-managing teams as an interdependent group with collective authority and responsibility of managing tasks (Dee, Henkin, \& Duemer, 2003). Members in self-managing teams uniquely characterized with an organic, bottom up structure typically perform better than traditional top-down control (Bolman \& Deal, 2013; Dee et al., 2003). Teacher teams at the research site did not have collective discretion to select content, schedule classes, group students, or choose assessments. Along with this, however, was the perception that they did have control to make decisions pertaining to grade level teams, including classroom goal setting, role specialization, and discipline to complete tasks. Though the principal selected specialized roles, teachers perceived managing themselves in their grade level group. Teachers perceived it to be an independent responsibility to organize and provide content-specific instruction and divide tasks among the groups, especially concerning the area of parental involvement. It was during informal meetings where teachers revealed personal needs, and group members offered suggestions or gestures of support.

5.2 RQ2: Using Covey's Maturity Continuum as the metric, at which maturity level do teachers at an identified low-performing Georgia Title I elementary school perceive their empowerment in relation to organizational structure? 
Participants at the low-performing Georgia Title I elementary school perceived there were various levels of maturity. Perception data was categorized on the Maturity Continuum from dependent (low) to interdependent (high). The maturity levels developed within RQ2 are as follows:

- Interdependent. Overall, they perceived some influence in decision-making through membership roles on committees. Shared decision-making would be an indicator of an empowering structural design if teachers made decisions that greatly affected the nature of their work (Covey, 2004; Daft, 2013; Short, 1994). After viewing the results, the researcher found teachers did not have the power to make decisions based on the structural arrangement.

- Independent. The majority of participants perceived their level of empowerment as independent, the second level of maturity. Participants perceived collaboration as an independent agreement. Battersby and Verdi (2015) defined collaboration as thoughtful interaction among teachers and the collective wisdom "generated by working together" (p. 25). The researcher suggests teachers were not empowered to work interdependently because of the structural configuration of team teaching, which had no shared content and only two to three teachers per grade level. It appeared communication (independent), rather than collaboration (interdependent), defined contributions to the group.

\subsection{RQ3: Using Covey's Maturity Continuum as the metric, what perceptions do teachers at an identified low- performing Georgia Title I elementary school have regarding the influence of the school's organizational structure and their ability to effectively work together?}

To determine the influence of the school's organizational structure and teachers' ability to effectively work together, a structural model was determined using perceptions of the school's organizational structure. This arrangement was framed using the ideas of Bolman and Deal's (2013) structural frame and Covey's (2004) Maturity Continuum. The school's model resembled a simple hierarchy, a top-down chain of command consisting of three levels of power (Bolman \& Deal, 2013). Participants described the organizational structure as a simple hierarchy, including vertical coordination of subordinates with district-level administration at the top, building-level administrators and instructional coach in the middle, teacher leaders below administrators, and grade level teams of teachers at the lowest level. All teachers served on one of the assigned teams. The researcher applied responsibility and authority, two major structural components, to identify teachers' perceptions of empowerment.

\subsubsection{Responsibility}

The keystone of organizational structure is the allocation of job roles, also known as responsibilities (Bolman \& Deal, 2013). Participants were dependent on administrators to allocate work and coordinate efforts among teams. In this low level of empowerment, administrators controlled the work of teachers through rules, policies, planning systems, and control systems (Bolman \& Deal, 2013; Green, 2000). Participants shared commitment in their responsibilities but lacked confidence related to imposed ideas on team goals. Administration used test scores for compliance. Participants called it "the push." Teachers seemed to believe the push was the organizational force, the call to action for duties and responsibilities. The push was a strong break in the progression of empowerment. More than the administrator, the data were perceived to control decisions regarding team functions.

\subsubsection{Authority}

The second structural factor known to impact empowerment is power to make decisions (Bolman \& Deal, 2013). Participants defined the organizational decision-making process as an alliance between leadership and teachers (Daft, 2013). This approach used centralized authority and processes to facilitate information sharing between administrators and teachers. As with role allocation, decisions were made using bargaining techniques when logical solutions to individual or team-based problems were communicated to leaders. Administrators, including authority over principals by system-level administrators, controlled complex decisions. Empowering structures represented teachers' beliefs that administrators support them in their work. The results suggested that teachers supported administrators in their work.

\subsubsection{Relationships}

The degree to which teachers were empowered was influenced by observable structural considerations, such as responsibility and authority. A less measurable structural consideration pertained to relationships among teachers. Through centralized coordination of meetings, communication networks were established among teachers. Participants presented a line of information sharing that started at the top with administrators, continued to the BST representatives, flowed to the various grade levels, and returned back up the ladder. With each level of communication, formal meetings were conducted to exchange ideas. These communication networks created social connections with access to collective knowledge, skill development, and ability (Pil \& Leana, 2009). Participants described a positive social context with frequent interactions influencing group performance. Participants revealed an independent level of empowerment at the individual level investing trust in fellow teachers to make them feel more powerful and able to take action on their own. 
A powerful, uncontrolled strategy created by team teachers was informal meetings after school that held everything in place over time. This meeting strategy that "glued things together" has been supported within past research (Bolman \& Deal, 2013, p. 54).

\section{Interpretation and Implications}

The purpose of this study was to determine the degree to which teachers were empowered by the school's organizational structure to effectively work together in an identified Title I elementary school using Covey's Maturity Continuum as the metric. Organizational structure, effective teamwork, and the Maturity Continuum were the major categories of this research study. The researcher suggests that interplay of these concepts creates structural conditions for leaders to consider in regards to successful organizational performance. Empowering organizational structures facilitate networks with multiple connections among team members (Bolman \& Deal, 2013). Participants in this study described a dependent structure consisting of a hierarchal network in which information flowed sequentially from principal to team leaders to teachers. The structural foundation either helps or hinders effectiveness (Bolman \& Deal, 2013). Effective teams operate under less formal authority through conditions of empowerment (Bolman \& Deal, 2013; Covey, 1993; Rutherford, 2006).

One implication of the study was that leaders move beyond mechanical approaches for understanding school organizations (Bolman \& Deal, 2013; Hampton \& Gruenert, 2008; Harris, 2013; Kanter, 1993; Pil \& Leana, 2009). Strategies that are focused on rules, policies, procedures, systems, and hierarchies encourage standardized opportunities for change. The problem with this thinking is the assumption that people, not policy, are responsible for doing the work. There is some evidence bureaucratic authority can be highly effective, especially when stability is a concern for the organization (Daft, 2012; Miles et al., 2010). On the other hand, present organizational theory research dismantled the traditional, bureaucratic structure and promoted a decentralized, informal organizational structure (Greenwood \& Miller, 2010; Suddaby, Hardy, \& Huy, 2011).

Another implication of the study was that leaders facilitate two forms of empowerment, both individual and team conditions. At the individual level, leaders encourage empowerment through clearly defined roles and shared decisionmaking. At both the individual and team levels, leaders may manage at various levels of empowerment based on the maturity level of their followers (Chen \& Rainey, 2014; Covey, 2004).Participants in this study revealed a unique organizational structure, which limits broad generalizability of findings.

\section{Recommendations}

The first recommendation is to replicate this study in Georgia Title I elementary schools with differing performance levels. The data collected among the various settings would add further credibility to this study. The second recommendation for future research includes interviewing administrators and comparing their perspectives to the perspectives of teachers. Analyzing both perceptions would add clarity to the purpose and selection of team configurations. A third recommendation to consider involves the new wave of charter schooling. Charter schools, by their nature and structure, require empowerment for all stakeholders, including teachers. Studies that look at similarities and differences between charter schools and their counterparts may provide interesting and helpful findings. The final recommendation is to entertain quantitative inquiry with the nature of this study. Empirical data is necessary in the field of education today to spark attention. A hybrid model for data collection where school test data are used to support qualitative findings may provide stronger interpretations. The school-wide focus on data within teachers' experiences revealed a pervasive need to use numbers as a tool to increase understanding of the lived experience. With these recommendations in mind, future research on organizational structure is encouraged for any stakeholders who become interested in its pursuit. 
Table 1. Sample of Data for the Concept of Centralized Structure

\begin{tabular}{|c|c|c|}
\hline Theme & Subcategories & Sample Categorical Data \\
\hline \multirow[t]{2}{*}{ Responsibility } & 1. Principal selects roles. & $\begin{array}{l}\text { They just assigned us. (Ruth) } \\
\text { Principal puts us in those roles.(Naomi) }\end{array}$ \\
\hline & Principal negotiates roles. & $\begin{array}{l}\text { Looked at the pros and cons of moving to a lower grade. } \\
\text { It's a good thing.(Wendy) }\end{array}$ \\
\hline \multirow[t]{3}{*}{ Authority } & $\begin{array}{l}\text { 1. Teachers } \\
\text { perceived simple } \\
\text { hierarchy arrangement. }\end{array}$ & $\begin{array}{l}\text { She is the main person in charge. I know she has } \\
\text { To do what she is told from the superintendent. (Ruth) } \\
\text { It's sort of like a chain.(Sophia) Administrators make sure } \\
\text { everybody's on the same page doing what we're supposed } \\
\text { to do from things pushed down from the county. (Wendy) }\end{array}$ \\
\hline & Power came from & $\begin{array}{l}\text { You have the administrator, and then me, and then we } \\
\text { have a team.(Naomi) }\end{array}$ \\
\hline & & $\begin{array}{l}\text { First person that would be in charge would be the } \\
\text { principal. (Shelby) }\end{array}$ \\
\hline
\end{tabular}

Note. Excerpts of sample data involved in subcategory development and thematic generation for the concept of centralized structure.

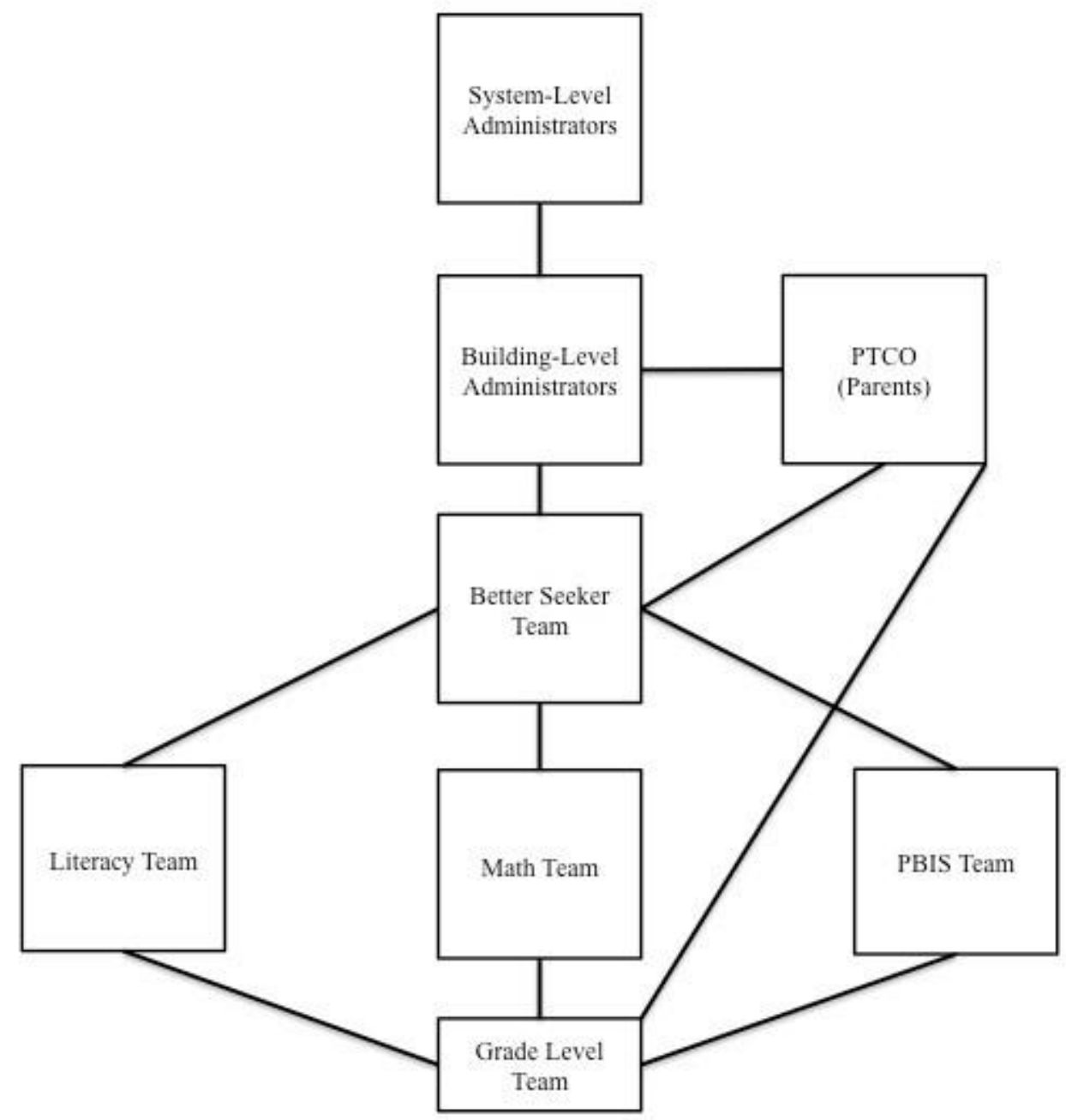

Figure 1. Diagram summarizing participants' perspectives on the organizational structure at their school. 


\section{References}

Battersby, S.L., \& Verdi, B. (2015). The culture of professional learning communities and connections to improve teacher efficacy and support student learning. Arts Education Policy Review, 116, $22-29$. doi:10.1080/10632913.2015.970096

Bolman, L. G., \& Deal, T. E. (2013). Reframing organizations (5th ed.). San Francisco, CA: Jossey-Bass.

Chen, C., \& Rainey, H. G. (2014). Personnel formalization and the enhancement of teamwork. Public Management Review, 16(7), 945-968. doi:10.1080/14719037.2013.770057

Covey, S. R. (1996). Principle centered leadership: What is empowerment? Retrieved from http://www.qualitydigest.com/jan/covey.html

Covey, S. R. (2004). The 7 habits of highly effective people. New York, NY: Free Press.

Daft, R. (2013). Understanding the theory and design of organizations (11th ed.). Mason, OH: South-Western, Cengage Learning.

Dee, J. R., Henkin, A.B., \& Duemer, L. (2003). Structural antecedents and psychological correlates of teacher empowerment. Journal of Educational Administration, 41(3), 257-277. doi:10.1108/09578230310474412

Goe, L, \& Stickler, L. (2008, March).Teacher quality and student achievement: Making the most of recent research(Issue Brief No. ED520769).Retrieved from https://eric.ed.gov/

Green, R. (2000). Natural forces: How to significantly increase student achievement in the third millennium. Monticello, FL: Educational Services Consortium, Inc.

Greenwood, R., \& Miller, D. (2010). Tackling design anew: Getting back to the heart of organizational theory. Academy of Management Perspectives, 24(4), 78-88. doi:10.5465/AMP.2010.55206386

Hampton, E. M., \& Gruenert, S. (2008). Social capital and school success: Combining internal and external commitment with school functioning factors. Journal of Ethnographic and Qualitative Research, 2, 163-172. Retrieved from http://www.jequr.org

Harris, A. (2013). Distributed leadership matters. Thousand Oaks, CA: Corwin.

Hourigan, R. (2011). Race to the Top: Implications for professional development in arts education. Arts Education Policy Review, 112(2), 60-64. doi:10.1080/14719037.2013.770057

Jimenez-Castellanos, O. (2010). Relationship between educational resources and school achievement: A mixed method intra-district analysis. Urban Review, 42(4), 351-371. doi:10.1007/s11256-010-0166-6

Kanter, R. M. (1993). Men and women of the corporation. New York, NY: BasicBooks.

Kini, T., \& Podolsky, A. (2016). Teaching experience and teacher effectiveness. American Educator, 40(3), 3. Retrieved from https://www.aft.org/our-news/periodicals/american-educator

Lightfoot, S. L. (1986). On goodness in schools: Themes of empowerment. Peabody Journal of Education, 63(3), 9-28. Retrieved from http://www.jstor.org/stable/1492663

Looney, J. (2011). Developing high-quality teachers: Teacher evaluation for improvement. European Journal of Education, 46(4), 440-455. doi:10.1111/j.1465-3435.2011.01492.x

Merriam, S. B. (2002). Qualitative research in practice: Examples for discussion and analysis. San Francisco, CA: Jossey-Bass.

Miles, M. B., Huberman, A. M., \& Saldana, J. (2014). Qualitative data analysis: A methods sourcebook. Thousand Oaks, CA: Sage Publications, Inc.

Nelson, S. W., \& Guerra, P. L. (2014). Educator beliefs and cultural knowledge: Implications for school improvement efforts. Educational Administration Quarterly, 50(1), 67-95. doi:10.1177/0013161X13488595

Office of the Governor. (2017). Deal's state of the state address: Georgia will accentuate the positive, eliminate the negative [Press Release]. Retrieved from https://gov.georgia.gov/press-releases/2017-0111/deal\%E2\%80\%99s-state-state-address-georgia-will-\%E2\%80\%98accentuate-positive-eliminate

Pil, F. K., \& Leana, C. (2009). Applying organizational research to public school reform: The effects of teacher human and social capital on student performance. Academy of Management Journal, 52(6), 1101-1124. doi:10.5465/AMJ.2009.47084647

Rogers-Chapman, M. F. (2015). Obama's education plan: The theory of action behind turning around America's worst schools. Education and Urban Society, 47(4), 476-495. doi:10.1177/0013124513497789

Rutherford, C. (2006). Teacher leadership and organizational structure: The implications of restructured leadership in an Edison school. Journal of Educational Change, 7(1), 59-76. doi:10.1007/s10833-006-0013-4

Seidman, I. (2006). Interviewing as qualitative research: A guide for researchers in education and the social sciences. New York, NY: Teachers College Press.

Short, P. M. (1994). School empowerment through self-managing teams: Leader behavior in developing self-managing work. Education, 114(4), 493-502. Retrieved from http://www.projectinnovation.com/education.html 
Smith, E., \& Gorard, S. (2007). Improving teacher quality: Lessons from America's No Child Left Behind. Cambridge Journal of Education, 37(2), 191-206. doi:10.1080/03057640701372426

Suddaby, R., Hardy, C., \& Huy, Q. N. (2011). Where are the new theories of organization? Academy of Management Review, 36(2), 236-246. doi:10.5465/AMR.2011.59330875

Waddell, C. (2011). School improvement grants: Ransoming Title I schools in distress. Current Issues in Education, 14(1). Retrieved from http://cie.asu.edu/

Wilson, N. M., \& Strassfeld, R. N. (2015). Turnaround in reverse: Brown, school improvement grants, and the legacy of educational opportunity. Cleveland State Law Review, 63(2), 373-396. Retrieved from http://www.law.csuohio.edu/ 